\title{
Rapid Aqueous-Phase Photooxidation of Dimers in the alpha-Pinene Secondary Organic Aerosol
}

\author{
Ran Zhao, Dana Aljawhary, Alex K. Y. Lee, and Jonathan. P. D. \\ Abbatt \\ Version Post-print/Accepted Manuscript \\ Citation Zhao, R., Aljawhary, D., Lee, A. K. Y., Abbatt, J. P. D., 2017. Rapid \\ (published version) Aqueous-Phase Photooxidation of Dimers in the alpha-Pinene \\ Secondary Organic Aerosol. Environ. Sci. Technol. Lett. 4, 205-210. \\ https://doi.org/10.1021/acs.estlett.7b00148. \\ Copyright / License This document is the Accepted Manuscript version of a Published \\ Work that appeared in final form in Environmental Science \& \\ Technology Letters, copyright (C) American Chemical Society after peer \\ review and technical editing by the publisher. To access the final edited \\ and published work see https://pubs.acs.org/doi/10.1021/ \\ acs.estlett.7b00148.
}

How to cite TSpace items

\begin{abstract}
Always cite the published version, so the author(s) will receive recognition through services that track citation counts, e.g. Scopus. If you need to cite the page number of the author manuscript from TSpace because you cannot access the published version, then cite the TSpace version in addition to the published version using the permanent URI (handle) found on the record page.
\end{abstract}

This article was made openly accessible by $U$ of $T$ Faculty. Please tell us how this access benefits you. Your story matters. 


\title{
Rapid Aqueous-phase Photooxidation of Dimers in $\alpha$-Pinene SOA
}

\author{
Ran Zhao, ${ }^{* \dagger, \ddagger}$ Dana Aljawhary, ${ }^{*}$ Alex K. Y. Lee,,$\$$ and Jonathan. P. D. Abbatt \\ $\dagger$ Department of Chemistry, University of Toronto, Toronto, Canada, M5S 3H6 \\ $\ddagger$ Now at: Division of Chemistry and Chemical Engineering, California Institute of \\ Technology, Pasadena, CA, USA, 91801 \\ \Department of Chemistry, University of Toronto, Toronto, Canada \\ $\S$ Now at: Department of Civil and Environmental Engineering, National University of \\ Singapore, Singapore, 117576 \\ E-mail: rzhao@caltech.edu; dana.aljawhary@mail.utoronto.ca \\ Phone: 1-626-395-8928
}

\begin{abstract}
Chemical complexity significantly hinders our understanding of the formation and evolution of secondary organic aerosol (SOA), known to have impacts on air quality and global climate. Dimeric substances present in SOA comprise a major fraction of extremely low-volatile organic compounds (ELVOCs) which are especially poorly characterized. Using on-line mass spectrometry, we have investigated the aqueousphase $\mathrm{OH}$ oxidation of dimers present in the water-soluble fraction of SOA arising from ozonolysis of $\alpha$-pinene. This study highlights very rapid $\mathrm{OH}$ oxidation of dimeric compounds. In particular, using pinonic acid as a reference compound, we obtained $2^{\text {nd }}$ order rate constants for the loss of 12 dimers, with an average value of $1.3 \pm 0.5 \times 10^{9}$ $\mathrm{M}^{-1} \mathrm{~s}^{-1}$ at room temperature. For the first time, this study demonstrates that rapid
\end{abstract}


loss of dimeric compounds will occur in cloudwater, and potentially also in aqueous aerosol.

\section{Introduction}

Secondary organic aerosol (SOA) refers to the organic fraction of suspended submicron particulate matter generated in the atmosphere via oxidation of volatile organic compounds (VOCs) of both anthropogenic and natural origins. ${ }^{1}$ Due to the important role that SOA plays in air quality and global climate, the formation and evolution of SOA components have been a major area of interest in atmospheric chemistry in recent years. The chemical complexity of SOA, however, significantly hinders a molecular-level understanding of the composition and reactivity of SOA components. In particular, the chemistry of extremely low-volatile organic compounds (ELVOCs) ${ }^{2}$ currently represents one of the largest gaps in our knowledge.

Dimers belong to an important class of ELVOCs and have been observed in laboratorygenerated $\mathrm{SOA}^{3-9}$ ambient $\mathrm{SOA}^{10-13}$ as well as ambient fog water. ${ }^{14}$ Comprising a large number of trace compounds with highly variable structures and functionalities ${ }^{11}$ the separation and identification of individual dimers are highly challenging. Recent application of mass spectrometry has revealed the elemental composition and structures of a number of dimeric esters. ${ }^{6,8,12}$ During a typical atmospheric lifetime of SOA, dimers are subject to photochemical processing. While photochemical processing can also occur in the particle phase, ${ }^{15,16}$ when a particle is activated into a cloud droplet, the aerosol dimers can dissolve into the aqueous phase via nucleating scavenging ${ }^{17}$ and undergo aqueous-phase photochemistry. ${ }^{5,18-22}$ Despite an extensive database of the aqueous-phase $\mathrm{OH}$ reactivity of organic compounds, ${ }^{23,24}$ kinetic data for SOA dimers are lacking. Photochemistry of dimers has not been incorporated into cloudwater chemistry models, with one exception. ${ }^{25}$ Analysis of dimers at the molecular-level is a prerequisite for understanding their chemistry. Whereas, 
for atmospheric modeling, the concept of a generalized $\mathrm{OH}$ reactivity ${ }^{26}$ that represents the wide diversity of dimers is essential, given that a complete speciation of dimers is infeasible.

Using an advanced mass spectrometric laboratory technique, we investigate for the first time the aqueous-phase photooxidation of dimers arising from $\alpha$-pinene ozonolysis. This chemical system is an atmospherically-representative reaction system, and its dimers are the best documented. ${ }^{5,6,8,11,12}$ Our specific goals are to determine the $\mathrm{OH}$ reactivity of individual dimers, as well as to develop a generalized $\mathrm{OH}$-dimer reactivity that can be used in photochemical models.

\section{Materials and Methods}

This work is based on experiments performed in Aljawhary et al. ${ }^{5}$ and a schematic view of the setup is shown in Figure 1. Briefly, SOA was generated by introducing $\alpha$-pinene and $\mathrm{O}_{3}$ to a $1 \mathrm{~m}^{3}$ Teflon chamber used as a continuously stirred tank reactor. The residence time of air in the chamber was 1.6 hours. The experiments were performed under the dry condition $(<5 \% \mathrm{RH})$ without an $\mathrm{OH}$-scavenger so that the $\alpha$-pinene oxidation proceeded mostly via ozonolysis with partial contribution from the $\mathrm{OH}$ radical. $\mathrm{O}_{3}(600 \mathrm{ppb})$ and $\alpha$-pinene $(140$ ppb) were continuously injected to the chamber, establishing a steady state at 500 and 40 ppb, respectively. Once the mass concentration of SOA reached its steady state $(200 \mu \mathrm{g}$ $\mathrm{m}^{-3}$ ), particle samples were collected on a Teflon filter $(47 \mathrm{~mm}$ diameter and $2 \mu \mathrm{m}$ pore size) behind an $\mathrm{O}_{3}$ denuder. The mass of SOA collected for each sample was 0.5 to $0.7 \mathrm{mg}$. After collection, the filter was immediately shaken in $50 \mathrm{~mL}$ of milliQ water for $15 \mathrm{~min}$ to extract the water-soluble organic compounds (WSOC) in SOA. The WSOC solutions were stored frozen at $-30{ }^{\circ} \mathrm{C}$ until photooxidation experiments.

Aqueous-phase photooxidation was performed by exposing UVB radiation to the SOA extract contained in a glass bottle, with $1 \mathrm{mM}$ of $\mathrm{H}_{2} \mathrm{O}_{2}$ (Sigma-Aldrich, TraceSelect ${ }^{T M}$ ) added as the $\mathrm{OH}$ precursor. The photon flux in the system has been reported by Badali 
et al. ${ }^{27}$ The $\mathrm{OH}$ steady state concentration was approximately $1.1 \times 10^{-13} \mathrm{M}$, according to the decay rate of pinonic acid and its $\mathrm{OH}$ rate constant. ${ }^{28}$ The length of each photooxidation experiment was typically 4 hours while the solution was continuously stirred and cooled by an external fan to keep the solution temperature at approximately $28^{\circ} \mathrm{C}$.

The solution composition was monitored in-situ by Aerosol Chemical Ionization Time of Flight Mass Spectrometry (Aerosol-ToF-CIMS) described in detail elsewhere. ${ }^{5,28-31}$ Briefly, the reaction solution was constantly atomized, and the generated particles were passed through a heated metal line $\left(150^{\circ} \mathrm{C}\right)$ for thermo-desorption. Organic compounds volatilized in the heated line were introduced to an Aerodyne high-resolution time-of-flight CIMS for detection using three reagent ions: iodide $\left(\mathrm{I}\left(\mathrm{H}_{2} \mathrm{O}\right)_{n}^{-}\right)$, acetate $\left(\mathrm{CH}_{3} \mathrm{C}(\mathrm{O}) \mathrm{O}^{-}\right)$and protonated water clusters $\left(\left(\mathrm{H}_{2} \mathrm{O}\right)_{n} \mathrm{H}^{+}\right)$. Iodide detects multi-functional organic compounds that can participate in hydrogen-bonding with iodide. ${ }^{32,33}$ Acetate detects organic and inorganic acids that possesses a larger gas-phase acidity than acetic acid. ${ }^{34,35}$ Water clusters detect organic compounds with a proton affinity larger than that of the water clusters. ${ }^{5}$ Overall, these three reagent ions detect overlapping yet distinct groups of species. Given that previous studies have shown that irradiation alone initiates chemical reactions of WSOC, ${ }^{5,20,21}$ a control experiment was performed for each of the reagent ions to investigate the effect of light without added $\mathrm{H}_{2} \mathrm{O}_{2}$. Each OH-oxidation and control experiment employed a filter from an individual chamber experiment. In addition, positive matrix factorization (PMF) analysis was performed on the time resolved mass spectral observations from the iodide-OH experiment, as the iodide reagent ion detects a wide range of oxygenated compounds with a relatively uniform sensitivity. Please see SI Section S1. 


\section{Results and Discussion}

\section{Spectral Change during OH Oxidation}

As described in our previous work, ${ }^{5}$ WSOC in $\alpha$-pinene ozonolysis SOA is a highly complex mixture of organic compounds. The mass spectra of WSOC clearly exhibit a bimodal form, representing monomers and dimers (SI Figure S3). Significant changes of the mass spectra were observed in the $\mathrm{OH}$ oxidation experiments with all the three reagent ions. The $\mathrm{OH}$ oxidation resulted in a depletion of dimers and formation of monomers, confirming that dimers are not ion clusters forming in the instrument but independent chemical species. The PMF analysis of the overall, time-resolved mass spectrum resulted in three factors with, notably, the dimeric signals residing in the precursor factor (SI Section S1).

\section{OH Reactivity of Individual Dimers}

We focus on assigning specific peaks in the mass spectra to dimers in $\alpha$-pinene SOA that have been previously identified. ${ }^{6,8,12}$ Assigning elemental compositions for dimers is challenging, as many possible combinations exist. The iodide reagent ion simplifies the process through the formation of iodide-analyte clusters where the heteroatom, iodine, adds unique mass signatures. ${ }^{32}$ We have successfully performed the high resolution mass fitting for 12 major dimers among which 10 have been reported previously (Table 1). The mass resolution of the iodide mode is approximately $4000 \mathrm{~m} / \mathrm{z} \mathrm{m} / \mathrm{z}^{-1}$ at the dimer region, with a mass accuracy to within \pm 6 ppm.

The time profiles of three well-documented compounds undergoing $\mathrm{OH}$ oxidation are shown in Figure 2, with the other nine in SI Figure S4a. All the dimers reacted away by the end of the experiment, with a few of them exhibiting a small degree of formation at short times. To quantify the net decay rates of an individual dimer $\left(k_{\mathrm{D}}^{\mathrm{II}}\right)$, a relative kinetics method is employed, using pinonic acid (PIN) as the reference compound, where it is assumed that the ratio of PIN to other compounds in the atomizer output reflects that in the experimental 
solution. A relative kinetic plot (Figure 2b) follows Eqn 1:

$$
\ln \frac{[D]_{0}}{[D]_{t}}=\frac{k_{\mathrm{D}}^{\mathrm{II}}}{k_{\mathrm{PIN}}^{\mathrm{II}}} \ln \frac{[\mathrm{PIN}]_{0}}{[\mathrm{PIN}]_{t}},
$$

where $[D]_{t}$ and $[\mathrm{PIN}]_{t}$ are the signals of a dimer and PIN at time $t$, respectively, and $k_{\mathrm{PIN}}^{\mathrm{II}}$ is the aqueous-phase $\mathrm{OH}$ rate constant of PIN: $3.3 \times 10^{9} \mathrm{M}^{-1} \mathrm{~s}^{-1}{ }^{28}$ As shown in Figure $2 \mathrm{~b}$, plotting $\ln \left([D]_{0} /[D]_{t}\right)$ against $\ln \left([\mathrm{PIN}]_{0} /[\mathrm{PIN}]_{t}\right)$ results in linear data passing through the origin, with a slope equivalent to the ratio between $k_{\mathrm{D}}^{\mathrm{II}}$ and $k_{\mathrm{PIN}}^{\mathrm{II}}$. The relative kinetics plots for the other nine dimers are shown in SI Figure S4b, with the $k_{\mathrm{D}}^{\mathrm{II}}$ values summarized in Table 1. The $\mathrm{OH}$ oxidation of all the dimers is rapid, approaching the aqueous-phase diffusion limit. We note that although each species assigned in Table 1 is arising from one specific peak in the mass spectrum, it is possible that other isobaric compounds also contribute to the observed peak intensity.

In addition to kinetic information, the current work provides tentative mechanistic information for the dimer chemistry. Extracting exclusive mechanisms from each individual dimer in such a complex chemical system is challenging. In SI Section S3, we have performed a case study for pinyl-diaterpenyl ester, the most dominant dimer observed. We have employed a structure-activity relationship ${ }^{36,37}$ to evaluate the most likely reaction pathway and have investigated products from both fragmentation and functionalization reactions.

\section{OH Reactivity of the Total Dimer Content}

Due to the infeasibility of performing high resolution peak fitting for all the dimers, we have lumped unit mass resolution signals across the entire dimer region to represent the total dimer content of the SOA. For the iodide experiment, peaks from 450 to $600 \mathrm{~m} / \mathrm{z}$ were summed to cover as much of the dimer region as possible without overlapping with the monomer region (Figure S3a). Similarly, the mass range of 300 to $450 \mathrm{~m} / \mathrm{z}$ was selected for the acetate and water clusters experiments. 
A rapid decay of the total dimer signal is seen in $\mathrm{OH}$-oxidation experiments using all the three reagent ions. The results of the iodide experiment are shown in Figure 2c as an example, and those of the other two reagent ions are shown in SI Figure S5. The relative kinetics plots of the three experiments are shown in Figure 2d. An averaged dimer $\mathrm{OH}$ reactivity $\left(k_{\text {Davg }}^{\mathrm{II}}\right)$ is determined from each of the three OH-oxidation experiments (Table 1 ) and three $k_{\text {Davg }}^{\text {II }}$ values agree to within a factor of two. Since the three reagent ions detect different populations of organic compounds, we propose that the average of the three $k_{\text {Davg }}^{\mathrm{II}}$, $1.3 \pm 0.5 \times 10^{9} \mathrm{M}^{-1} \mathrm{~s}^{-1}$, can be employed as a generic $\mathrm{OH}$ rate constant of dimers arising from $\alpha$-pinene ozonolysis.

We note that the second-order rate constant for the decay of the precursor factor (Factor 1) in the PMF solution is $3.1 \times 10^{9} \mathrm{M}^{-1} \mathrm{~s}^{-1}$, obtained using the relative kinetics method mentioned above. Although containing the dimeric signals, Factor 1 is largely driven by intense monomeric peaks. The fact that the rate constants for decay of both dimers (i.e. $k_{\text {Davg }}^{\mathrm{II}}$ ) and Factor 1 are similar to those of a large variety of atmospherically-relevant organic compounds ${ }^{23}$ demonstrates uniform reactivity for a wide range of species, i.e. the dimers are inherently neither more reactive nor more stable with respect to $\mathrm{OH}$ oxidation than monomeric species in solution.

Currently, the aqueous-phase $\mathrm{OH}$ reactivity of dimers is poorly constrained. Ervens et al. ${ }^{25}$ have reported the $\mathrm{OH}$ reactivity of methylvinyl ketone oligomers $\left(1 \times 10^{8} \mathrm{M}^{-1}\right.$ $\mathrm{s}^{-1}$ ), obtained by fitting experimental observations in a chemical system in which dimers formed and reacted simultaneously. The strength and novelty of this work lie in the in-situ measurement of the decaying dimers that are actually extracted from $\alpha$-pinene SOA. The $k_{\text {Davg }}^{\mathrm{II}}$ value determined in this work provides a significant experimental constraint to the aqueous-phase $\mathrm{OH}$ reactivity of dimers.

One experimental uncertainty in this work arises from the potential for direct photolysis of dimers with UVB light. Direct photolysis of aqueous dimers has been observed. ${ }^{18-21}$ Nevertheless, our best estimate is that direct photolysis contributes at most a few $\%$ of 
the dimer decay observed during the $\mathrm{OH}$ oxidation experiments. See SI Section $\mathrm{S} 4$ for details. We also note that chemical processes occurring in the irradiated WSOC solution are highly complex, making the decoupling of direct photolysis and $\mathrm{OH}$ oxidation difficult. In particular, studies have shown that WSOC of SOA itself can generate OH radicals. ${ }^{27,38}$ Meanwhile, the aqueous-phase formation of oligomers has also been reported, ${ }^{39-43}$ as was observed to a minor degree at early times for a couple of dimers in this work (see Figure S4 and Section S3.3). Thus, the kinetic information reported in the current work should be considered as an effective $\mathrm{OH}$-oxidation rate coefficient, representing the net decay of dimers upon exposure to $\mathrm{OH}$ in aqueous media (e.g., cloudwater).

\section{Environmental Implications}

On-line mass spectrometry was applied to investigate the aqueous-phase $\mathrm{OH}$ reactivity of the water-soluble fraction of SOA arising from $\alpha$-pinene ozonolysis, with a specific focus on dimers present in this complex system. By directly observing the decay of specific dimeric species, and supported by positive matrix factorization analysis of the full CIMS spectrum, we demonstrate that dimeric compounds undergo aqueous-phase photochemical processing and contribute to monomeric products.

Building upon recent studies that have identified dimers in the $\alpha$-pinene system, we have quantified for the first time the effective second-order rate constants $\left(k_{\mathrm{D}}^{\mathrm{II}}\right)$ of 12 individual dimers. As well, the rate coefficients of the total dimer $\left(k_{\text {Davg }}^{\mathrm{II}}\right)$, measured using three different reagent ions of the CIMS agree to within a factor of two. We propose that the average value $\left(1.3 \times 10^{9} \mathrm{M}^{-1} \mathrm{~s}^{-1}\right)$ can be used in multi- and aqueous-phase models as a generic rate constant for $\mathrm{OH}$ oxidation of dimers in biogenic SOA dominated by reactions of monoterpenes. While this study focused on a specific category of dimers from $\alpha$-pinene, future studies should investigate the reactivity of a wider spectrum of extremely low-volatile organic compounds (ELVOCs) arising in both laboratory experiments and the ambient atmosphere. 
More generally, the environmental significance of this result is that it further illustrates that $\mathrm{OH}$ oxidation in cloudwater can be an efficient sink of a number of organic species. ${ }^{44}$ These include not only monomeric tracer compounds (such as levoglucosan and 3-methyl1,2,3-butanetricarboxylic acid (MBTCA) $)^{28,31}$ and brown carbon species, ${ }^{45}$ but also dimers. The $k_{\text {Davg }}^{\text {II }}$ value from this work can be translated into an e-fold lifetime of 2.1 hours in cloudwater, assuming an $\mathrm{OH}$ concentration of $1 \times 10^{-13} \mathrm{M}^{23}$. The ratio of dimers to monomers in SOA may represent an unique tracer for condensed-phase processing and should be investigated in the future. Our results imply an important role of the aqueous phase in removing organic compounds in the atmosphere, as it has been previously shown that aging of SOA particles under dry conditions did not remove dimers efficiently. ${ }^{46}$ While the current work simulates dilute cloudwater-relevant conditions, aqueous-phase $\mathrm{OH}$ oxidation can be potentially important in aerosol liquid water, where the concentrations of both reactants and oxidants are highly uncertain. ${ }^{26}$

Investigation of the identity and formation pathways of dimers in SOA is a major current priority in atmospheric chemistry, as dimers may constitute a sizable fraction of SOA mass. ${ }^{8,12}$ The dimers investigated in this work represent a poorly characterized fraction of SOA component, e.g., ELVOCs, and the reactive sink evaluated in this work is one of the first studies of the dimer chemistry. Overall, aqueous-phase sinks should be taken into consideration when the environmental fate of ELVOCs and related highly-oxygenated compounds is assessed.

\section{Acknowledgement}

The authors thank CFI for the purchase of the CIMS. Operational support comes from NSERC, OGS, Environment Canada Graduate Supplements and the Alex Harrison Award. The authors also note extensive help from M. Willis (Abbatt Group) for the PMF analysis. 


\section{Supporting Information Available}

Additional information for the PMF analysis and kinetic data are available.

This material is available free of charge via the Internet at http://pubs.acs.org/.

\section{References}

(1) Seinfeld, J. H.; Pandis, S. N. Atmospheric Chemistry and Physics: From Air Pollution to Climate Change, 3rd ed.; John Wiley \& Sons, Hoboken, New Jersey, 2016.

(2) Ehn, M.; Thornton, J. A.; Kleist, E.; Sipila, M.; Junninen, H.; Pullinen, I.; Springer, M.; Rubach, F.; Tillmann, R.; Lee, B.; et al., A Large Source of Low-volatility Secondary Organic Aerosol. Nature 2014, 506, 476-479.

(3) Kalberer, M.; Paulsen, D.; Sax, M.; Steinbacher, M.; Dommen, J.; Prevot, A. S. H.; Fisseha, R.; Weingartner, E.; Frankevich, V.; Zenobi, R.; et al., Identification of Polymers as Major Components of Atmospheric Organic Aerosols. Science 2004, 303, 1659-1662.

(4) Müller, L.; Reinnig, M.-C.; Warnke, J.; Hoffmann, T. Unambiguous Identification of Esters as Oligomers in Secondary Organic Aerosol Formed from Cyclohexene And Cyclohexene/ $\alpha$-pinene Ozonolysis. Atmos. Chem. Phys. 2008, 8, 1423-1433.

(5) Aljawhary, D.; Lee, A. K. Y.; Abbatt, J. P. D. High-resolution Chemical Ionization Mass Spectrometry (ToF-CIMS): Application to Study SOA Composition and Processing. Atmos. Mea. Tech. 2013, 6, 3211-3224.

(6) Kristensen, K.; Cui, T.; Zhang, H.; Gold, A.; Glasius, M.; Surratt, J. D. Dimers in $\alpha$-pinene Secondary Organic Aerosol: Effect of Hydroxyl Radical, Ozone, Relative Humidity and Aerosol Acidity. Atmos. Chem. Phys. 2014, 14, 4201-4218.

(7) Kristensen, K.; Enggrob, K. L.; King, S. M.; Worton, D. R.; Platt, S. M.; Mortensen, R.; Rosenoern, T.; Surratt, J. D.; Bilde, M.; Goldstein, A. H.; et al., Formation and Occur- 
rence of Dimer Esters of Pinene Oxidation Products in Atmospheric Aerosols. Atmos. Chem. Phys. 2013, 13, 3763-3776.

(8) Zhang, X.; McVay, R. C.; Huang, D. D.; Dalleska, N. F.; Aumont, B.; Flagan, R. C.; Seinfeld, J. H. Formation and Evolution of Molecular Products in $\alpha$-pinene Secondary Organic Aerosol. PNAS 2015, 112, 14168-14173.

(9) Tu, P.; Hall, W. A.; Johnston, M. V. Characterization of Highly Oxidized Molecules in Fresh and Aged Biogenic Secondary Organic Aerosol. Anal. Chem. 2016, 88, 44954501.

(10) Denkenberger, K. A.; Moffet, R. C.; Holecek, J. C.; Rebotier, T. P.; Prather, K. A. RealTime, Single-Particle Measurements of Oligomers in Aged Ambient Aerosol Particles. Environ. Sci. Technol. 2007, 41, 5439-5446.

(11) Mutzel, A.; Poulain, L.; Berndt, T.; Iinuma, Y.; Rodigast, M.; Böge, O.; Richters, S.; Spindler, G.; Sipilä, M.; Jokinen, T.; et al., Highly Oxidized Multifunctional Organic Compounds Observed in Tropospheric Particles: A Field and Laboratory Study. Environ. Sci. Technol. 2015, 49, 7754-7761.

(12) Kristensen, K.; Watne, A. K.; Hammes, J.; Lutz, A.; Petäjä, T.; Hallquist, M.; Bilde, M.; Glasius, M. High-Molecular Weight Dimer Esters are Major Products in Aerosols from $\alpha$-Pinene Ozonolysis and the Boreal Forest. Environ. Sci. Technol. Lett. 2016, 3, 280-285.

(13) Yasmeen, F.; Vermeylen, R.; Maurin, N.; Perraudin, E.; Doussin, J.-F.; Claeys, M. Characterisation of Tracers for Aging of $\alpha$-Pinene Secondary Organic Aerosol Using Liquid Chromatography/Negative Ion Electrospray Ionisation Mass Spectrometry. Environ. Chem. 2012, 9, 236-246.

(14) Mazzoleni, L. R.; Ehrmann, B. M.; Shen, X.; Marshall, A. G.; Collett, J. L. WaterSoluble Atmospheric Organic Matter in Fog: Exact Masses and Chemical Formula Iden- 
tification by Ultrahigh-Resolution Fourier Transform Ion Cyclotron Resonance Mass Spectrometry. Environ. Sci. Technol. 2010, 44, 3690-3697.

(15) Epstein, S. A.; Blair, S. L.; Nizkorodov, S. A. Direct Photolysis of $\alpha$-Pinene Ozonolysis Secondary Organic Aerosol: Effect on Particle Mass and Peroxide Content. Environ. Sci. Technol. 2014, 48, 11251-11258.

(16) Wong, J.; Zhou, S.; Abbatt, J. Changes in Secondary Organic Aerosol Composition and Mass Due to Photolysis: Relative Humidity Dependence. J. Phys. Chem. A 2014, 119, 4309-4316.

(17) Herckes, P.; Valsaraj, K. T.; Collett Jr, J. L. A Review of Observations of Organic Matter in Fogs and Clouds: Origin, Processing and Fate. Atmos. Res. 2013, 132, 434449.

(18) Bateman, A. P.; Nizkorodov, S. A.; Laskin, J.; Laskin, A. Photolytic Processing of Secondary Organic Aerosols Dissolved in Cloud Droplets. Phys. Chem. Chem. Phys. 2011, 13, 12199-12212.

(19) Nguyen, T. B.; Laskin, A.; Laskin, J.; Nizkorodov, S. A. Direct Aqueous Photochemistry of Isoprene High-NO $\mathrm{NO}_{x}$ Secondary Organic Aerosol. Phys. Chem. Chem. Phys. 2012, 14, 9702-9714.

(20) Romonosky, D. E.; Laskin, A.; Laskin, J.; Nizkorodov, S. A. High-Resolution Mass Spectrometry and Molecular Characterization of Aqueous Photochemistry Products of Common Types of Secondary Organic Aerosols. J. Phys. Chem. A 2014, 119, 25942606.

(21) Romonosky, D. E.; Ali, N. N.; Saiduddin, M. N.; Wu, M.; Lee, H. J. J.; Aiona, P. K.; Nizkorodov, S. A. Effective Absorption Cross Sections and Photolysis Rates of Anthropogenic and Biogenic Secondary Organic Aerosols. Atmos. Environ. 2016, 130, $172-179$. 
(22) Romonosky, D. E.; Li, Y.; Shiraiwa, M.; Laskin, A.; Laskin, J.; Nizkorodov, S. A. Aqueous Photochemistry of Secondary Organic Aerosol of $\alpha$-Pinene and $\alpha$-Humulene Oxidized with Ozone, Hydroxyl Radical, and Nitrate Radical. J. Phys. Chem. A 2017, 121, 1298-1309.

(23) Herrmann, H.; Hoffmann, D.; Schaefer, T.; Braeuer, P.; Tilgner, A. Tropospheric Aqueous-phase Free-radical Chemistry: Radical Sources, Spectra, Reaction Kinetics and Prediction Tools. Chemphyschem 2010, 11, 3796-3822.

(24) Herrmann, H.; Schaefer, T.; Tilgner, A.; Styler, S. A.; Weller, C.; Teich, M.; Otto, T. Tropospheric Aqueous-Phase Chemistry: Kinetics, Mechanisms, and Its Coupling to a Changing Gas Phase. Chem. Rev. 2015, 115, 4259-4334.

(25) Ervens, B.; Renard, P.; Tlili, S.; Ravier, S.; Clément, J.-L.; Monod, A. Aqueous-Phase Oligomerization of Methyl Vinyl Ketone through Photooxidation - Part 2: Development of the Chemical Mechanism and Atmospheric Implications. Atmos. Chem. Phys. 2015, 15, 9109-9127.

(26) Arakaki, T.; Anastasio, C.; Kuroki, Y.; Nakajima, H.; Okada, K.; Kotani, Y.; Handa, D.; Azechi, S.; Kimura, T.; Tsuhako, A.; et al., A General Scavenging Rate Constant for Reaction of Hydroxyl Radical with Organic Carbon in Atmospheric Waters. Environ. Sci. Technol. 2013, 47, 8196-8203.

(27) Badali, K. M.; Zhou, S.; Aljawhary, D.; Antiñolo, M.; Chen, W. J.; Lok, A.; Mungall, E.; Wong, J. P. S.; Zhao, R.; Abbatt, J. P. D. Formation of Hydroxyl Radicals from Photolysis of Secondary Organic Aerosol Material. Atmos. Chem. Phys. 2015, 15, 7831-7840.

(28) Aljawhary, D.; Zhao, R.; Lee, A. K.; Wang, C.; Abbatt, J. P. Kinetics, Mechanism and Secondary Organic Aerosol Yield of Aqueous Phase Photo-oxidation of $\alpha$-Pinene Oxidation Products. J. Phys. Chem. A 2015, 120, 1395-1407. 
(29) Hearn, J. D.; Smith, G. D. A Chemical Ionization Mass Spectrometry Method for the Online Analysis of Organic Aerosols. Anal. Chem. 2004, 76, 2820-2826.

(30) Sareen, N.; Schwier, A. N.; Shapiro, E. L.; Mitroo, D.; McNeill, V. F. Secondary Organic Material Formed by Methylglyoxal in Aqueous Aerosol Mimics. Atmos. Chem. Phys. 2010, 10, 997-1016.

(31) Zhao, R.; Mungall, E. L.; Lee, A. K.; Aljawhary, D.; Abbatt, J. P. Aqueous-phase Photooxidation of Levoglucosan - A Mechanistic Study Using Aerosol Time-of-Flight Chemical Ionization Mass Spectrometry (Aerosol ToF-CIMS). Atmos. Chem. Phys. 2014, 14, 9695-9706.

(32) Lee, B. H.; Lopez-Hilfiker, F.; Mohr, C.; Kurtén, T. C.; Worsnop, D.; Thornton, J. A. An Iodide-Adduct High-Resolution Time-of-Flight Chemical-Ionization Mass Spectrometer: Application to Atmospheric Inorganic and Organic Compounds. Environ. Sci. Technol. 2014, 48, $6309-6317$.

(33) Lopez-Hilfiker, F. D.; Lee, B. H.; D'Ambro, E. L.; Thornton, J. A. Constraining the Sensitivity of Iodide Adduct Chemical Ionization Mass Spectrometry to Multifunctional Organic Molecules Using the Collision Limit and Thermodynamic Stability of Iodide Ion Adducts. Atmos. Mea. Tech. 2016, 9, 1505.

(34) Bertram, T. H.; Kimmel, J. R.; Crisp, T. A.; Ryder, O. S.; Yatavelli, R. L. N.; Thornton, J. A.; Cubison, M. J.; Gonin, M.; Worsnop, D. R. A Field-deployable, Chemical Ionization Time-of-Flight Mass Spectrometer. Atmos. Mea. Tech. 2011, 4, 1471-1479.

(35) Veres, P.; Roberts, J. M.; Warneke, C.; Welsh-Bon, D.; Zahniser, M.; Herndon, S.; Fall, R.; de Gouw, J. Development of negative-ion proton-transfer chemical-ionization mass spectrometry (NI-PT-CIMS) for the measurement of gas-phase organic acids in the atmosphere. Int. J. Mass Spectrom. 2008, 274, 48-55. 
(36) Monod, A.; Doussin, J. Structure-activity relationship for the estimation of OHoxidation rate constants of aliphatic organic compounds in the aqueous phase: alkanes, alcohols, organic acids and bases. Atmos. Environ. 2008, 42, 7611-7622.

(37) Doussin, J.-F.; Monod, A. Structure-activity relationship for the estimation of OHoxidation rate constants of carbonyl compounds in the aqueous phase. Atmos. Chem. Phys. 2013, 13, 11625-11641.

(38) Tong, H.; Arangio, A. M.; Lakey, P. S. J.; Berkemeier, T.; Liu, F.; Kampf, C. J.; Brune, W. H.; Pöschl, U.; Shiraiwa, M. Hydroxyl Radicals from Secondary Organic Aerosol Decomposition in Water. Atmos. Chem. Phys. 2016, 16, 1761-1771.

(39) Lim, Y. B.; Tan, Y.; Perri, M. J.; Seitzinger, S. P.; Turpin, B. J. Aqueous Chemistry and Its Role in Secondary Organic Aerosol (SOA) Formation. Atmos. Chem. Phys. 2010, 10, 10521-10539.

(40) Lim, Y. B.; Tan, Y.; Turpin, B. J. Chemical Insights, Explicit Chemistry, and Yields of Secondary Organic Aerosol from OH Radical Oxidation of Methylglyoxal and Glyoxal in the Aqueous Phase. Atmos. Chem. Phys. 2013, 13, 8651-8667.

(41) Liu, Y.; Siekmann, F.; Renard, P.; Zein, A. E.; Salque, G.; Haddad, I. E.; TemimeRoussel, B.; Voisin, D.; Thissen, R.; Monod, A. Oligomer and SOA Formation through Aqueous Phase Photooxidation of Methacrolein and Methyl Vinyl Ketone. Atmos. Environ. 2012, 49, $123-129$.

(42) Renard, P.; Siekmann, F.; Salque, G.; Demelas, C.; Coulomb, B.; Vassalo, L.; Ravier, S.; Temime-Roussel, B.; Voisin, D.; Monod, A. Aqueous-Phase Oligomerization of Methyl Vinyl Ketone through Photooxidation - Part 1: Aging Processes of Oligomers. Atmos. Chem. Phys. 2015, 15, 21-35.

(43) Tan, Y.; Lim, Y.; Altieri, K.; Seitzinger, S.; Turpin, B. Mechanisms Leading to 
Oligomers and SOA through Aqueous Photooxidation: Insights from Oh Radical Oxidation of Acetic Acid and Methylglyoxal. Atmos. Chem. Phys. 2012, 12, 801-813.

(44) Ervens, B. Modeling the Processing of Aerosol and Trace Gases in Clouds and Fogs. Chem. Rev. 2015, 115, 4157-4198.

(45) Zhao, R.; Lee, A. K. Y.; Huang, L.; Li, X.; Yang, F.; Abbatt, J. P. D. Photochemical Processing of Aqueous Atmospheric Brown Carbon. Atmos. Chem. Phys. 2015, 15, 6087-6100.

(46) Kourtchev, I.; Doussin, J.-F.; Giorio, C.; Mahon, B.; Wilson, E. M.; Maurin, N.; Pangui, E.; Venables, D. S.; Wenger, J. C.; Kalberer, M. Molecular composition of fresh and aged secondary organic aerosol from a mixture of biogenic volatile compounds: a high-resolution mass spectrometry study. Atmos. Chem. Phys. 2015, 15, 5683-5695.

(47) Müller, L.; Reinnig, M.-C.; Hayen, H.; Hoffmann, T. Characterization of oligomeric compounds in secondary organic aerosol using liquid chromatography coupled to electrospray ionization Fourier transform ion cyclotron resonance mass spectrometry. Rapid Commun. Mass Spectrom. 2009, 23, 971-979.

(48) Witkowski, B.; Gierczak, T. Early stage composition of SOA produced by $\alpha$ pinene/ozone reaction: $\alpha$-Acyloxyhydroperoxy aldehydes and acidic dimers. Atmos. Environ. 2014, 95, 59-70.

(49) Gao, Y.; Hall IV, W.; Johnston, M. Molecular composition of monoterpene secondary organic aerosol at low mass loading. Environ. Sci. \& Technol. 2010, 44, 7897-7902.

(50) Yasmeen, F.; Vermeylen, R.; Szmigielski, R.; Iinuma, Y.; Böge, O.; Herrmann, H.; Maenhaut, W.; Claeys, M. Terpenylic acid and related compounds: precursors for dimers in secondary organic aerosol from the ozonolysis of $\alpha$-and $\beta$-pinene. Atmos. Chem. Phys. 2010, 10, 9383-9392. 
(51) Beck, M.; Hoffmann, T. A detailed $\mathrm{MS}^{n}$ study for the molecular identification of a dimer formed from oxidation of pinene. Atmos. Environ. 2016, 130, 120 - 126. 
Table 1: A list of individual dimers and their $\mathrm{OH}$ rate constant $\left(k_{\mathrm{D}}^{\mathrm{II}}\right)$, as well as the average $\mathrm{OH}$ reactivity of SOA dimer content $\left(k_{\text {Davg }}^{\mathrm{II}}\right)$. The three compounds highlighted in colors are those presented in Figure 2a and $\mathrm{b}$

\begin{tabular}{|c|c|c|c|c|}
\hline $\begin{array}{c}\text { Observed } \\
\mathrm{m} / \mathrm{z}\end{array}$ & $\begin{array}{l}\text { Dimer Nominal } \\
\text { Mass }\left(\mathrm{g} \mathrm{mol}^{-1}\right) \\
\end{array}$ & $\begin{array}{c}\text { Proposed } \\
\text { Dimer Formula }\end{array}$ & $\begin{array}{c}k_{\mathrm{D}}^{\mathrm{II}} \\
\left(\mathrm{M}^{-1} \mathrm{~s}^{-1}\right)^{a}\end{array}$ & Ref. \\
\hline 453 & 326 & $\mathrm{C}_{16} \mathrm{H}_{22} \mathrm{O}_{7}$ & $1.5 \times 10^{9}$ & n.a. \\
\hline 455 & 328 & $\mathrm{C}_{16} \mathrm{H}_{24} \mathrm{O}_{7}$ & $1.6 \times 10^{9 b}$ & 12,47 \\
\hline 467 & 340 & $\mathrm{C}_{18} \mathrm{H}_{28} \mathrm{O}_{6}$ & $2.4 \times 10^{9}$ & $12,47,48$ \\
\hline 469 & 342 & $\mathrm{C}_{17} \mathrm{H}_{26} \mathrm{O}_{7}$ & $2.8 \times 10^{9}$ & $12,47,49$ \\
\hline 471 & 344 & $\begin{array}{c}\mathrm{C}_{16} \mathrm{H}_{24} \mathrm{O}_{8} \\
\text { (pinyl-diaterbyl ester) }\end{array}$ & $9.5 \times 10^{8}$ & $6,8,12,47$ \\
\hline 485 & 358 & $\begin{array}{c}\mathrm{C}_{17} \mathrm{H}_{26} \mathrm{O}_{8} \\
\text { (pinyl-diaterpenyl ester) }\end{array}$ & $2.6 \times 10^{9}$ & $6-8,12,47,50$ \\
\hline 495 & 368 & $\begin{array}{c}\mathrm{C}_{19} \mathrm{H}_{28} \mathrm{O}_{7} \\
\text { (pinonyl-pinyl ester) }\end{array}$ & $4.8 \times 10^{9}$ & $4,6-8,12,47,49-51$ \\
\hline 501 & 374 & $\mathrm{C}_{17} \mathrm{H}_{26} \mathrm{O}_{9}$ & $1.2 \times 10^{9 b}$ & 12 \\
\hline 511 & 384 & $\mathrm{C}_{19} \mathrm{H}_{28} \mathrm{O}_{8}$ & $3.6 \times 10^{9}$ & 12 \\
\hline 515 & 388 & $\mathrm{C}_{18} \mathrm{H}_{28} \mathrm{O}_{9}$ & $2.0 \times 10^{9}$ & 6,12 \\
\hline 527 & 400 & $\mathrm{C}_{19} \mathrm{H}_{28} \mathrm{O}_{9}$ & $3.2 \times 10^{9}$ & 8,12 \\
\hline \multirow[t]{6}{*}{529} & 402 & $\mathrm{C}_{19} \mathrm{H}_{30} \mathrm{O}_{9}$ & $1.9 \times 10^{9}$ & n.a. \\
\hline & & Expt. & $\begin{array}{c}k_{\text {Davg }}^{I I} \\
\left(\mathrm{M}^{-1} \mathrm{~s}^{-1}\right)\end{array}$ & \\
\hline & & Iodide & $1.6 \times 10^{9}$ & \\
\hline & & Acetate & $1.5 \times 10^{9}$ & \\
\hline & & Water cluster & $7.0 \times 10^{8}$ & \\
\hline & & Average & $(1.3 \pm 0.5) \times 10^{9}$ & \\
\hline
\end{tabular}

${ }^{a}$ Derived from the $\mathrm{OH}$ oxidation experiment using the iodide reagent ion.

${ }^{b}$ This compound exhibits an initial formation, and the $k_{\mathrm{D}}^{\mathrm{II}}$ value is derived from the later decay. 


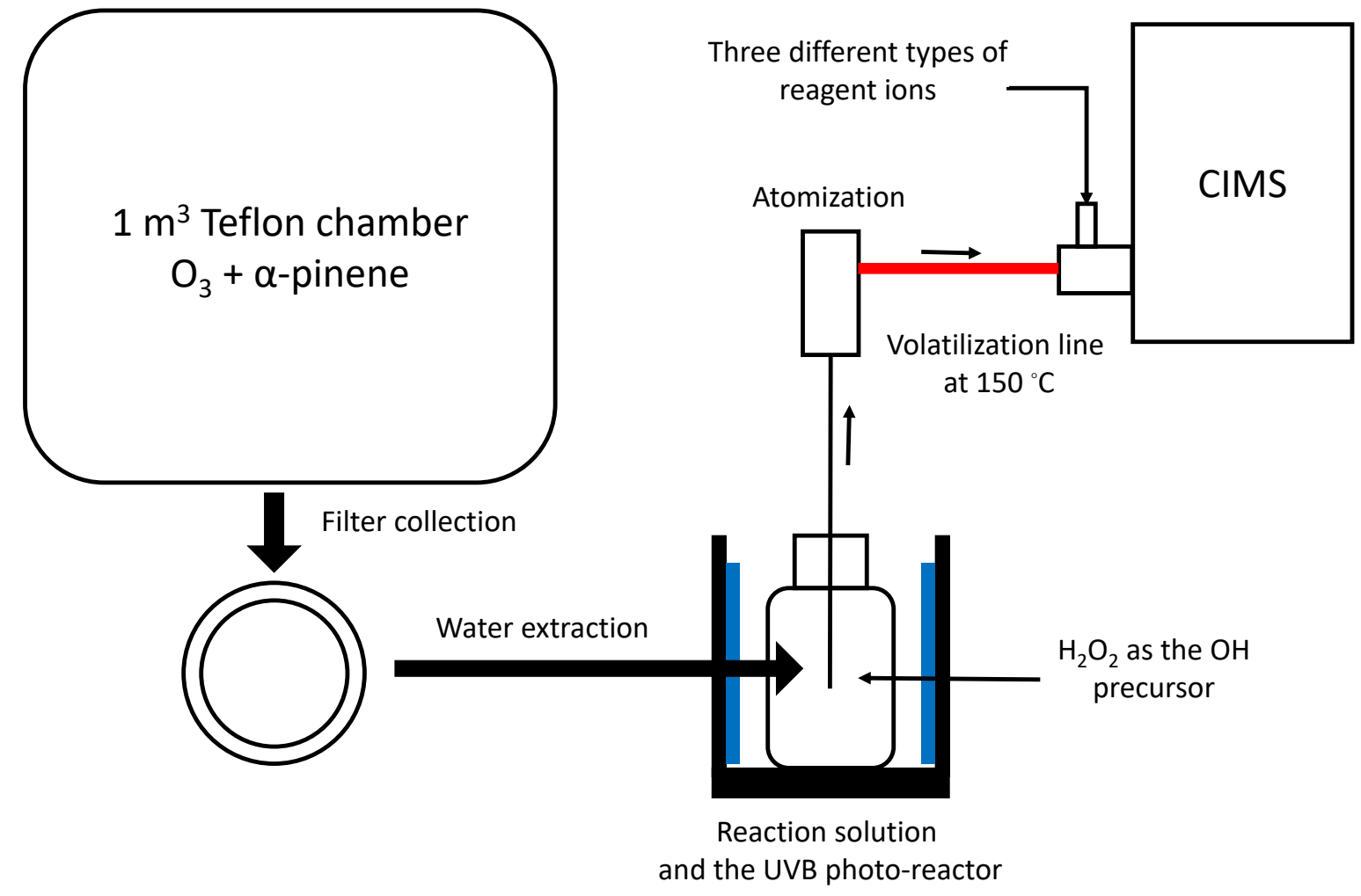

Figure 1: Experimental apparatus. 

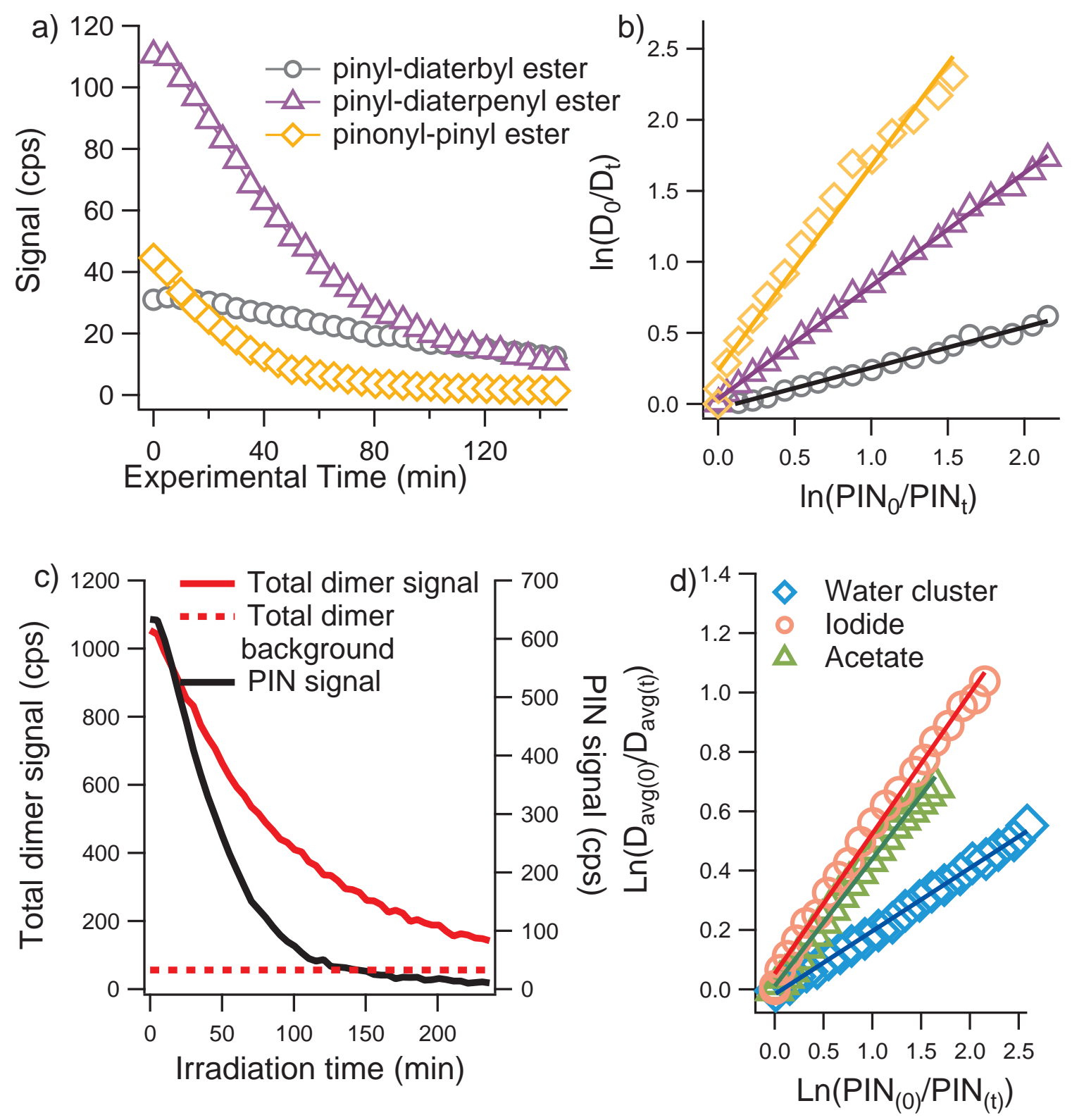

Figure 2: The time series (a) and relative kinetics plots (b) of three individual dimers, as well as those of the lumped total dimer signals (c and d). For clarity, only the total dimer signal from the iodide experiment is shown in (c) along with the decay profile of pinonic acid (PIN) as a reference. The dashed line presents the mass spectral background of the total dimer signal. The solid lines in (b) and (d) are the linear fit curves. 


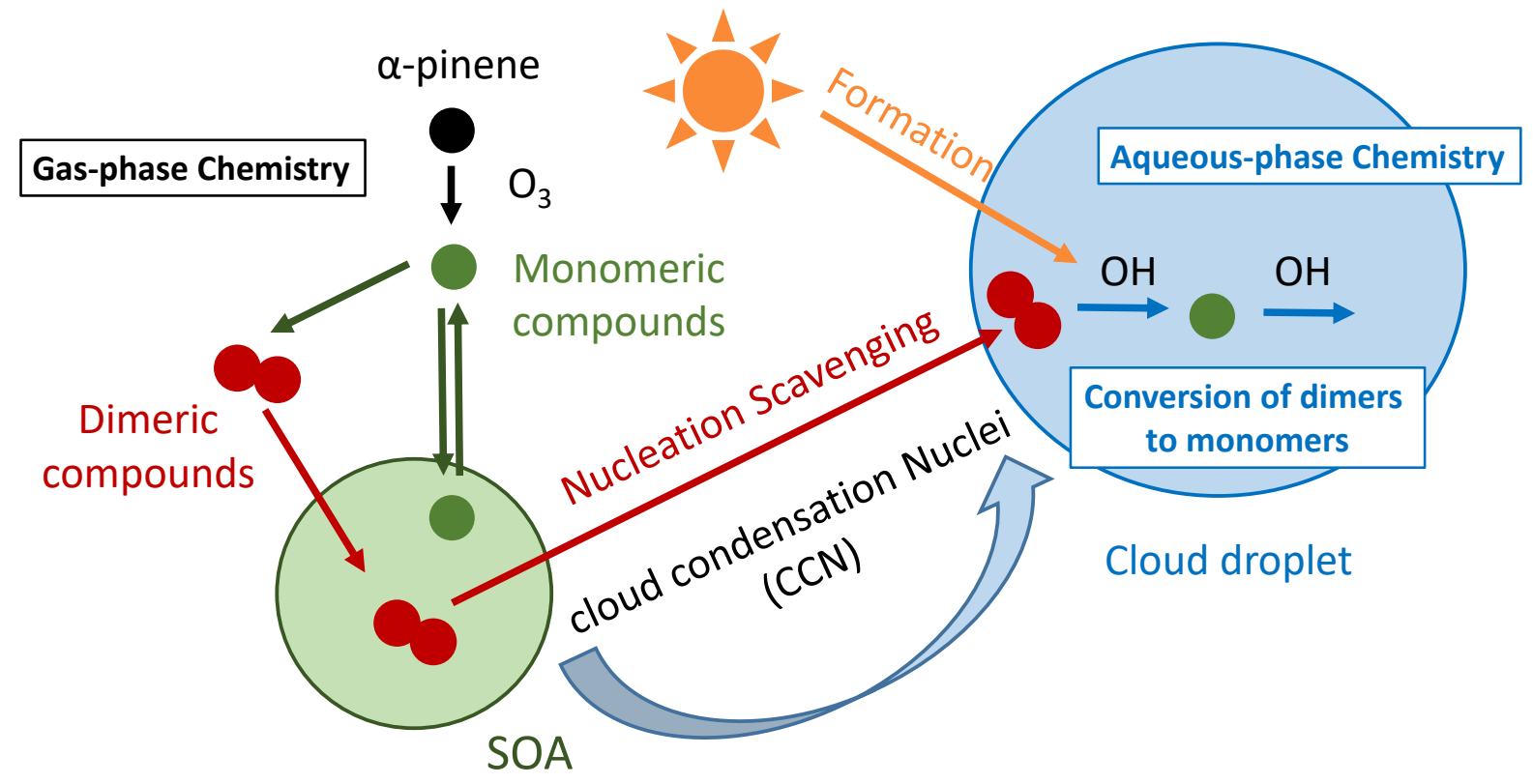

Figure 3: This is the TOC graphic. 